\title{
Topical tranexamic acid reduces transfusion rates in simultaneous bilateral total knee arthroplasty: a retrospective case series
}

\author{
Christopher Kim, MD, MSc \\ Sam S. Park, MD \\ Herman S. Dhotar, MD, MPH \\ Anthony V. Perruccio, PhD \\ Michael G. Zywiel, MD, MSc \\ J. Roderick Davey, MD
}

\begin{abstract}
This work was presented at the American Academy of Orthopaedic Surgeons 2015 Annual Meeting and 70th Canadian Orthopaedic Association 2015 Annual Meeting.
\end{abstract}

Accepted Feb. 6, 2017; Early-released Aug. 1, 2017

\section{Correspondence to: \\ J.R. Davey \\ Division of Orthopedic Surgery \\ Toronto Western Hospital \\ 399 Bathurst St, 1E-444 \\ Toronto ON M5T 2S8 \\ rod.davey@uhn.ca}

DOI: $10.1503 /$ cjs. 014716
Background: Topical tranexamic acid (TA) has been reported to be effective in reducing postoperative bleeding and transfusions after total knee arthroplasty (TKA). The main objective of this study was to retrospectively assess the effectiveness and safety of topical TA administration in patients undergoing simultaneous bilateral TKA.

Methods: We conducted a retrospective chart review of consecutive cohorts of patients undergoing simultaneous bilateral TKA. We compared the patients who received TA with patients from a similar time frame who did not receive TA. For those who received TA, a topical concentration of $2 \mathrm{~g}$ per $30 \mathrm{~mL}$ of normal saline was used in each knee. Preoperative and postoperative hemoglobin, transfusions, length of stay (LOS) and postoperative complications were recorded for each patient until discharge. Outcome measures were analyzed using independent $t$ test, $\chi^{2}$ test and logistic regression.

Results: We included 49 patients in our analysis: 25 who received TA and 24 who did not. There were no statistical differences in demographics between the groups. The rate of transfusion in the TA group was $4 \%$ compared with $67 \%$ in the non-TA group $(p<0.001)$. The net hemoglobin loss in the TA group was $4.1 \mathrm{~g} / \mathrm{dL}$ versus $6.2 \mathrm{~g} / \mathrm{dL}$ in the non-TA group $(p<0.001)$. The use of TA was found to be associated with a greater than $99 \%$ reduced risk of receiving a transfusion (odds ratio 0.003 , $95 \%$ confidence interval $<0.001-0.072, p<0.001)$. There were no thromboembolic events in patients who received TA, and there was 1 pulmonary embolus in the nonTA group. Postoperative LOS was significantly reduced in the TA group (mean difference $1.1 \mathrm{~d}, p=0.005)$.

Conclusion: Topical administration of TA in patients undergoing simultaneous bilateral TKA significantly reduced transfusions, blood loss and postoperative LOS, with no increased risk of thromboembolic events.

Contexte : Selon certains rapports, l'acide tranexamique (AT) topique réduirait efficacement les saignements postopératoires et le recours aux transfusions après une intervention pour prothèse totale du genou. Le principal objectif de cette étude était d'évaluer de manière rétrospective l'efficacité et l'innocuité de l'AT topique chez des patients soumis à une intervention pour prothèse totale des 2 genoux.

Méthodes : Nous avons procédé à une analyse rétrospective des dossiers de cohortes consécutives de patients soumis à une intervention pour prothèse totale des 2 genoux. Nous avons comparé les patients ayant reçu l'AT aux patients d'une période similaire qui n'ont pas reçu l'AT. Pour ceux qui ont reçu l'AT, la concentration topique de $2 \mathrm{~g}$ par $30 \mathrm{~mL}$ de solution physiologique a été utilisée dans les 2 genoux. On a enregistré chez chaque patient les taux d'hémoglobine pré- et postopératoires, le nombre de transfusions, la durée du séjour hospitalier et les complications postopératoires jusqu’à leur congé. Les paramètres ont été analysés à l'aide du test $t, d u$ test du $\chi^{2}$ et de la régression logistique.

Résultats : Nous avons inclus 49 patients dans notre analyse : 25 ayant reçu l'AT et 24 ne l'ayant pas reçu. Il n'y avait aucune différence statistique entre les groupes pour ce qui est des caractéristiques démographiques. Le taux de transfusions dans le groupe ayant reçu l'AT a été de $4 \%$, contre $67 \%$ dans le groupe n'ayant pas reçu l'AT ( $p<$ 0,001). La baisse nette de l'hémoglobine dans le groupe ayant reçu l'AT a été de $4,1 \mathrm{~g} / \mathrm{dL}$, contre $6,2 \mathrm{~g} / \mathrm{dL}$ dans le groupe n'ayant pas reçu l'AT $(p<0,001)$. L'utilisation de l'AT a été associée à une réduction de plus de $99 \%$ du risque de transfusion (rapport des cotes 0,003, intervalle de confiance de $95 \%<0,001-0,072$, $p<0,001)$. On n'a noté aucun incident thromboembolique chez les patients ayant reçu l'AT, et une embolie pulmonaire dans le groupe n'ayant pas reçu l'AT. La durée du 
séjour hospitalier postopératoire a été significativement plus brève dans le groupe ayant reçu l'AT (différence moyenne $1,1 \mathrm{j}, p=0,005$ ).

Conclusion : L'administration topique d'AT chez des patients soumis à une intervention pour prothèse totale des 2 genoux a significativement réduit le recours aux transfusions et les pertes sanguines et a abrégé les séjours hospitaliers postopératoires, sans accroître le risque d'incidents thromboemboliques.

n the United States, approximately 7\% of 611000 total knee arthroplasties (TKAs) were simultaneous bilateral procedures. ${ }^{1}$ The potential advantages of simultaneous bilateral TKA include single anesthetic, reduced length of stay (LOS) in hospital, decreased rehabilitation time and decreased associated hospital costs. ${ }^{2}$ It is still debated whether the benefits outweigh a potential increase in morbidity and mortality. There are several studies that suggest there is no difference in complication rates between simultaneous bilateral TKA compared with unilateral TKA. ${ }^{3-5}$ However, in a meta-analysis by Restrepo and colleagues, ${ }^{6}$ simultaneous bilateral TKA was reported to be associated with a 2-fold greater risk of serious cardiac complications, pulmonary complications and death than unilateral TKA. ${ }^{6}$ In the largest data set comparing unilateral TKA with simultaneous bilateral TKA, Odum and colleagues ${ }^{7}$ reported increased risk of both minor and major in-hospital complications and death in patients undergoing simultaneous bilateral TKA. Similarly, the systematic review by Fu and colleagues ${ }^{8}$ found that simultaneous bilateral TKA increased rates of cardiovascular incidents and venous thromboembolic events and increased the need for perioperative blood product transfusion.

Substantial blood loss and the need for subsequent blood transfusions are of potential concern in patients undergoing simultaneous bilateral TKA and may be one of the causes of increased complications. The average number of units of blood transfused in patients undergoing simultaneous bilateral TKA has been found to be greater than the number transfused in those undergoing unilateral TKA., ${ }^{9} 10$ The increased duration of surgery, use of a thigh tourniquet associated with increased risk of localized fibrinolysis, and hypothermia are plausible explanations for greater blood loss with simultaneous bilateral TKA than unilateral TKA. ${ }^{2}$ Thus, blood management in simultaneous bilateral TKA is often more challenging than in unilateral TKA. Recently, topical tranexamic acid (TA) has been reported to be an effective and inexpensive method to reduce postoperative bleeding after unilateral joint replacement. ${ }^{11-19}$

The main objective for our study was to assess the effectiveness and safety of topical TA administration in patients undergoing simultaneous bilateral TKA based on objective clinical outcome measures.

\section{Methods}

We conducted a retrospective chart review to identify consecutive patients undergoing simultaneous bilateral TKA for primary osteoarthritis between Feb. 28, 2012, (when routine topical TA was introduced) and Apr. 8, 2014, at a single academic institution. A control group of patients undergoing simultaneous bilateral TKA without the use of TA between Sept. 4, 2008, and Jan. 31, 2012, was identified and used for the comparative analysis. We set the study end date for April 2014 to allow for at least 1 year of follow-up after surgery for all patients included in the study. We excluded patients with diagnoses other than osteoarthritis (e.g., trauma and rheumatoid arthritis). The research ethics board of the University Health Network, Toronto, Ont., Canada, approved our study.

All simultaneous bilateral TKAs were performed in a similar fashion by the senior author (J.R.D.). Thigh tourniquets were inflated before skin incision and deflated after skin closure. In all cases, TKA was completed on the first side before the contralateral side was begun. A medial parapatellar approach and cemented TKA components were used in all patients. The patella was resurfaced in select patients. Surgical drains were not used. Within the TA group, a solution of $2 \mathrm{~g}$ of TA dissolved in $30 \mathrm{~mL}$ of $0.9 \%$ normal saline was instilled in each wound after implantation of the final components, left for 3 minutes and then removed with suction. The wound was not washed again thereafter and was then closed. Venous thromboembolism prophylaxis was given to all patients, consisting of $40 \mathrm{mg}$ of enoxaparin administered subcutaneously for 10 days postoperatively starting on postoperative day 1 .

We assessed clinical outcomes using objective measures. We identified participant characteristics of the case and control groups. Demographic data included age, sex and body mass index (BMI). Preoperative comorbidities that would affect either bleeding or thromboembolism as well as active use of anticoagulants was identified. Laboratory values, including hemoglobin, international normalized ratio (INR), activated partial thromboplastin time (aPTT) and platelet count, were obtained preoperatively and every day postoperatively and extracted from patient charts until the day of discharge. Additionally, the number of units of blood transfused; occurrence of medical complications, such as deep venous thrombosis (DVT) and pulmonary embolism (PE); and total length of hospital stay (LOS) were identified. Guidelines for transfusion in our institution involved a conservative strategy in which blood was transfused on a postoperative hemoglobin level of less than $8 \mathrm{~g} / \mathrm{dL}$, or less than $10 \mathrm{~g} / \mathrm{dL}$ if the patient experienced symptoms of anemia or organ 
dysfunction that may have been caused or exacerbated by anemia and not another cause. The primary outcome measures were postoperative transfusion rates and the difference between preoperative hemoglobin and the corresponding lowest postoperative value. Secondary outcome measures included venous thromboembolic events and LOS.

\section{Statistical analysis}

Statistics were calculated between the TA group and the non-TA group. We used a paired $t$ test to compare means between the groups. Transfusion rates between groups were compared using a $\chi^{2}$ test for categorical data. The effect of TA on the risk of transfusion, age, sex, BMI, preoperative hemoglobin and preoperative platelet count was calculated using logistic regression analysis. We calculated odds ratios (ORs), 95\% confidence intervals (CIs) and 2 -tailed $p$ values, with the type 1 error rate $(\alpha)$ set at 0.05 . We conducted all analyses using SAS software version 9.1 for UNIX (SAS Institute).

\section{Results}

A total of 49 patients undergoing simultaneous bilateral TKA were identified. Twenty-four patients underwent simultaneous bilateral TKA without TA and 25 patients underwent the same procedure with routine use of TA.

\begin{tabular}{|c|c|c|c|}
\hline \multirow[b]{2}{*}{ Characteristic } & \multicolumn{2}{|c|}{ Group; mean \pm SD or $\%$} & \multirow[b]{2}{*}{$p$ value } \\
\hline & Non-TA $(n=24)$ & $\mathrm{TA}(n=25)$ & \\
\hline Age, yr & $63.6 \pm 9.6$ & $62.3 \pm 8.7$ & 0.60 \\
\hline Female sex & 45.8 & 46.2 & 0.98 \\
\hline $\mathrm{BMI}$ & $30.5 \pm 5.7$ & $28.4 \pm 5.7$ & 0.20 \\
\hline INR & $0.97 \pm 0.06$ & $0.97 \pm 0.07$ & 0.84 \\
\hline aPTT, s & $29.1 \pm 1.8$ & $29.0 \pm 1.8$ & 0.87 \\
\hline $\begin{array}{l}\text { Platelet count, } \\
\times 10^{9} / \mathrm{L}\end{array}$ & $245.7 \pm 35.9$ & $263.3 \pm 46.8$ & 0.14 \\
\hline Hemoglobin, g/dL & $14.4 \pm 1.25$ & $13.7 \pm 1.08$ & 0.041 \\
\hline
\end{tabular}

Table 2. Postoperative outcomes
\begin{tabular}{|lccc|}
\hline & Group; mean \pm SD or no. $(\%)$ & \\
\cline { 2 - 3 } & Non-TA $(n=24)$ & TA $(n=25)$ & $p$ value \\
\hline Outcome & $16(66.7)$ & $1(4.0)$ & $<0.001$ \\
\hline No. of patients transfused & 28 & 1 & \\
\hline $\begin{array}{l}\text { No. of units transfused } \\
\text { Postoperative } \\
\text { hemoglobin, g/dL }\end{array}$ & $8.16 \pm 1.43$ & $9.61 \pm 1.48$ & $<0.001$ \\
\hline Hemoglobin loss, g/dL & $6.24 \pm 1.25$ & $4.10 \pm 0.93$ & $<0.001$ \\
\hline LOS, $d$ & $4.4 \pm 1.6$ & $3.3 \pm 0.8$ & 0.005 \\
\hline LOS = length of stay; SD = standard deviation; TA = tranexamic acid. & \\
\hline
\end{tabular}

All cases were consecutive and performed for primary knee osteoarthritis.

There were no significant differences in preoperative age, sex, BMI, INR, aPTT, or platelet count between the groups, except the preoperative hemoglobin was higher in the nonTA group than the TA group $(14.4 \mathrm{~g} / \mathrm{dL}$ v. $13.7 \mathrm{~g} / \mathrm{dL}, p=$ 0.041 ; Table 1). No patients reported anticoagulant use, history of bleeding, or thrombotic risk factors.

The rate of transfusion in the TA group was $4.0 \%$ compared with $66.7 \%$ in the non-TA group $(p<0.001)$. The use of topical TA in simultaneous bilateral TKA resulted in greater postoperative hemoglobin levels $(9.61 \pm 1.48 \mathrm{~g} / \mathrm{dL}$ v. $8.16 \pm 1.43 \mathrm{~g} / \mathrm{dL}, p<0.001)$, reduced net hemoglobin loss $(4.1 \pm 0.93 \mathrm{~g} / \mathrm{dL}$ v. $6.24 \pm 1.25 \mathrm{~g} / \mathrm{dL}, p<0.001)$ and significantly reduced LOS $(3.3 \pm 0.8 \mathrm{~d} \mathrm{v} .4 .4 \pm 1.6 \mathrm{~d}, p=0.005$; Table 2).

Logistic regression analysis revealed that the administration of TA in patients undergoing simultaneous bilateral TKA was associated with a greater than $99 \%$ reduced risk of having a transfusion postoperatively (OR $0.003,95 \%$ CI $<0.001-0.072, p<0.001)$.

There were no thromboembolic events in the TA group and $1 \mathrm{PE}$ in the non-TA group. None of the patients had clinical evidence for DVT, infection or wound complications.

\section{Discussion}

In the present study, topical administration of TA in patients undergoing simultaneous bilateral TKA compared with controls significantly reduced transfusion requirements, blood loss and postoperative LOS, with no increased risk of thromboembolic events.

A recent study by Hegde and colleagues ${ }^{20}$ investigated the use of topical TA in patients undergoing simultaneous bilateral TKA. The authors conducted a prospective study comparing postoperative blood loss and blood requirement after simultaneous bilateral computerassisted TKA in 3 groups with administration of $10 \mathrm{~mL}$ of $0.9 \%$ normal saline intravenously alone, $10 \mathrm{~mL}$ of intravenous (IV) TA alone, and $1 \mathrm{~g}$ of intra-articular TA alone in each knee. According to their results, there was a $61 \%$ reduction in postoperative blood loss and an $88 \%$ reduction in postoperative blood requirement in the intra-articular TA group compared with the control group. The authors reported no DVT, PE, infection or wound complications in the intra-articular TA group. ${ }^{20}$ Our study found similar results with the use of a solution of $2 \mathrm{~g}$ of TA dissolved in $30 \mathrm{~mL}$ of $0.9 \%$ normal saline in each wound after implantation of the final components. Our findings are consistent with the meta-analysis literature showing that higher doses of topical TA had a greater effect on the reduction of blood loss and transfusion rate..$^{21,22}$ Our rate of transfusion in the TA group was $4.0 \%$ compared with $66.7 \%$ in the non-TA group, and 
administration of TA in patients undergoing simultaneous bilateral TKA resulted in a more than $99 \%$ reduced odds of requiring a transfusion postoperatively.

A significant finding in our study was that the routine use of topical TA significantly decreased postoperative LOS, with a mean difference of 1.1 days. Husted and colleagues ${ }^{23}$ previously reported that a blood transfusion is the main predictor of increased LOS after TKA, even extending mean LOS 3-fold. ${ }^{23}$

Topical tranexamic acid is contraindicated in patients with history of DVT or PE, intrinsic risk for thrombosis or thromboembolism, acute renal failure, subarachnoid hemorrhage, history of seizures, hypersensitivity and allergy to TA. ${ }^{24}$ Owing to the possible risk of increased thrombosis using TA, numerous studies have excluded patients with a history of thromboembolism. However, this potential risk has not been shown in randomized controlled trials (RCTs) using TA. In a prospective, double-blinded RCT, Wong and colleagues ${ }^{17}$ compared $1.5 \mathrm{~g}$ and $3.0 \mathrm{~g}$ doses of topical TA to an equal volume of normal saline in 99 patients undergoing unilateral, cemented primary TKA. In their study, 35 patients received normal saline, 31 patients received $1.5 \mathrm{~g}$ of topical TA, and 33 patients received $3.0 \mathrm{~g}$ of topical TA. Topical TA was applied to the wound after all components were cemented into place and left for 5 minutes. Both doses of topical TA resulted in a significant decrease in blood loss and transfusion requirements, with minimal systemic absorption and no increase in venous thromboembolic events. ${ }^{17}$ In another prospective, double-blinded, RCT, Alshryda and colleagues ${ }^{15}$ compared topical TA to normal saline in 157 patients undergoing unilateral, cemented primary TKA. In their study, 78 patients received normal saline and 79 patients received $1 \mathrm{~g}$ of topical TA. The topical TA group had a higher postoperative hemoglobin level and a significant reduction in the transfusion rate, with an absolute risk reduction of $15.4 \%$ in the TA group. There were no differences in the incidence of DVT between the normal saline and TA groups. ${ }^{15}$

Topical TA can be a viable alternative in patients with contraindications to IV TA, such as increased risk of thromboembolism or acute renal failure. One of the advantages of topical TA is the minimal systemic absorption. Wong and colleagues ${ }^{17}$ reported that plasma levels of topical TA were approximately $70 \%$ lower than an equivalent dose of IV TA. The mean plasma levels after application of low $(1.5 \mathrm{~g})$ and high $(3.0 \mathrm{~g})$ doses of topical TA were $4.5 \mathrm{mg} / \mathrm{L}$ and $8.5 \mathrm{mg} / \mathrm{L}$, respectively, whereas the plasma level 1 hour after administration of $10 \mathrm{mg} / \mathrm{kg}$ of IV TA was $18 \mathrm{mg} / \mathrm{L} .^{17,25}$ Two recent meta-analyses showed that topical TA was safe, with no increase in DVT or PE..$^{21,22}$ Of the patients included in our study, there were no thromboembolic events in the topical TA group and $1 \mathrm{PE}$ in the non-TA group.

\section{Limitations}

Owing to the nature of the study design, there were some associated limitations. The retrospective design of the study made it difficult to control perioperative variables, such as demographic characteristics and comorbidities. Additionally, the study involved a relatively small sample size given the rare incidence of bilateral TKA cases. A power analysis was not performed.

Additionally, as this was based on patient population at a single institution, the results may not be generalizable to an entire population. However, considering the results of the study were based on consecutive patients at a single institution and TKA performed by a single surgeon, there was less variability in the care provided to patients, providing more consistent results.

\section{Conclusion}

Topical administration of TA in patients undergoing simultaneous bilateral TKA compared with controls showed significantly reduced transfusion requirements, blood loss and postoperative LOS, with no increased risk of thromboembolic events. Topical TA should be considered for routine use in patients undergoing simultaneous bilateral TKA to decrease blood loss. Approving and extending the indications for the use of TA in simultaneous bilateral TKA would be a useful measure to reduce blood loss and transfusion rates.

Affiliation: From the Division of Orthopaedic Surgery, Toronto Western Hospital, Toronto, Ont.

Competing interests: J.R. Davey declares consultancy fees, speaker fees and travel assistance from Zimmer Biomet. No other competing interests declared.

Contributors: C. Kim, H. Dhotar, A. Perruccio and J.R. Davey designed the study. C. Kim, S. Park, H. Dhotar, M. Zywiel and J.R. Davey acquired the data, which C. Kim, S. Park and A. Perruccio analyzed. C. Kim wrote the article, which all authors reviewed and approved for publication.

\section{References}

1. Barrett J, Baron JA, Losina E, et al. Bilateral total knee replacement: staging and pulmonary embolism. 7 Bone foint Surg Am 2006;88: 2146-51.

2. Patil N, Wakankar H. Morbidity and mortality of simultaneous bilateral total knee arthroplasty. Orthopedics 2008;31:780-9.

3. Alemparte J, Johnson GV, Worland RL, et al. Results of simultaneous bilateral total knee replacement: a study of 1208 knees in 604 patients. 7 South Orthop Assoc 2002;11:153-6.

4. Cohen RG, Forrest CJ, Benjamin JB. Safety and efficacy of bilateral total knee arthroplasty. 7 Arthroplasty 1997;12:497-502.

5. Hooper GJ, Hooper NM, Rothwell AG, et al. Bilateral total joint arthroplasty: the early results from the New Zealand National Joint Registry. 7 Arthroplasty 2009;24:1174-7.

6. Restrepo C, Parvizi J, Dietrich T, et al. Safety of simultaneous bilateral total knee arthroplasty. A meta-analysis. 7 Bone foint Surg Am 2007; 89:1220-6 
7. Odum SM, Springer BD. In-hospital complication rates and associated factors after simultaneous bilateral versus unilateral total knee arthroplasty. F Bone foint Surg Am 2014;96:1058-65.

8. Fu D, Li G, Chen K, et al. Comparison of clinical outcome between simultaneous-bilateral and staged-bilateral total knee arthroplasty: a systematic review of retrospective studies. F Arthroplasty 2013;28:1141-7.

9. Adili A, Bhandari M, Petruccelli D, et al. Sequential bilateral total knee arthroplasty under 1 anesthetic in patients $>$ or $=75$ years old: complications and functional outcomes. F Arthroplasty 2001;16:271-8.

10. Bullock DP, Sporer SM, Shirreffs TG Jr. Comparison of simultaneous bilateral with unilateral total knee arthroplasty in terms of perioperative complications. 7 Bone foint Surg Am 2003;85-A:1981-6.

11. Chimento GF, Huff T, Ochsner JL, et al. An evaluation of the use of topical tranexamic acid in total knee arthroplasty. 7 Arthroplasty 2013;28:74-7.

12. Gilbody J, Dhotar HS, Perruccio AV, et al. Topical tranexamic acid reduces transfusion rates in total hip and knee arthroplasty. 7 Arthroplasty 2014;29:681-4.

13. Konig G, Hamlin BR, Waters JH. Topical tranexamic acid reduces blood loss and transfusion rates in total hip and total knee arthroplasty. 7 Arthroplasty 2013;28:1473-6.

14. Georgiadis AG, Muh SJ, Silverton CD, et al. A prospective doubleblind placebo controlled trial of topical tranexamic acid in total knee arthroplasty. F Arthroplasty 2013;28:78-82.

15. Alshryda S, Mason J, Vaghela M, et al. Topical (intra-articular) tranexamic acid reduces blood loss and transfusion rates following total knee replacement: a randomized controlled trial (TRANX-K). $\mathcal{F}$ Bone foint Surg Am 2013;95:1961-8.
16. Ishida K, Tsumura N, Kitagawa A, et al. Intra-articular injection of tranexamic acid reduces not only blood loss but also knee joint swelling after total knee arthroplasty. Int Orthop 2011;35:1639-45.

17. Wong J, Abrishami A, El Beheiry H, et al. Topical application of tranexamic acid reduces postoperative blood loss in total knee arthroplasty: a randomized, controlled trial. 7 Bone foint Surg Am 2010; 92:2503-13.

18. Roy SP, Tanki UF, Dutta A, et al. Efficacy of intra-articular tranexamic acid in blood loss reduction following primary unilateral total knee arthroplasty. Knee Surg Sports Traumatol Artbrosc 2012;20:2494-501.

19. Panteli M, Papakostidis C, Dahabreh Z, et al. Topical tranexamic acid in total knee replacement: a systematic review and meta-analysis. Knee 2013;20:300-9.

20. Hegde C, Wasnik S, Kulkarni S, et al. Simultaneous bilateral computer assisted total knee arthroplasty: the effect of intravenous or intraarticular tranexamic acid. 7 Arthroplasty 2013;28:1888-91.

21. Panteli M, Papakostidis C, Dahabreh Z, et al. Topical tranexamic acid in total knee replacement: a systematic review and meta-analysis. Knee 2013;20:300-9.

22. Yue $\mathrm{C}$, Pei F, Yang $\mathrm{P}$, et al. Effect of topical tranexamic acid in reducing bleeding and transfusions in TKA. Orthopedics 2015;38:315-24.

23. Husted H, Holm G, Jacobsen S. Predictors of length of stay and patient satisfaction after hip and knee replacement surgery: fast-track experience in 712 patients. Acta Orthop 2008;79:168-73.

24. Tengborn L, Blombäck M, Berntorp E. Tranexamic acid-an old drug still going strong and making a revival. Thromb Res 2015;135:231-42.

25. Nilsson IM. Clinical pharmacology of aminocaproic and tranexamic acids. 7 Clin Pathol Suppl (R Coll Pathol) 1980;14:41-7. 